\title{
Effect of Nitric Oxide Synthase Inhibition during Group B Streptococcal Sepsis in Neonatal Piglets
}

\author{
RONALD L. GIBSON, JAMES I. BERGER, GREGORY J. REDDING, \\ THOMAS A. STANDAERT, DENNIS E. MAYOCK, AND WILLIAM E. TRUOG \\ Department of Pediatrics, University of Washington School of Medicine, \\ Seattle, Washington 98195
}

\begin{abstract}
Nitric oxide (NO), an important vasodilatory modulator
of systemic and pulmonary vascular tone, is synthesized from $\mathrm{L}$-arginine by the enzyme NO synthase in vascular endothelial and smooth muscle cells. L-Arginine analogs, such as $\mathrm{N}^{\omega}$-nitro-L-arginine methyl ester (L-NAME), are competitive antagonists of NO synthase and inhibit NO synthesis. Group B streptococcus (GBS) causes pulmonary hypertension, hypoxemia, lung vascular injury, and reduced cardiac output in both human newborns and neonatal piglets. Lung vascular injury associated with prolonged GBS infusion in piglets may attenuate NO production and thus promote severe pulmonary hypertension. We studied the effect of the NOS inhibitor, L-NAME and the precursor of NO, L-arginine, on pulmonary and systemic hemodynamics during late-phase GBS sepsis in the piglet model. Neonatal piglets were anesthetized, ventilated with room air, and randomized to receive a continuous infusion of saline $(n=5)$ or GBS $(n=5)$ for $4 \mathrm{~h}$. After $3 \mathrm{~h}$ of infusion, both groups received a bolus of L-NAME $(3 \mathrm{mg} / \mathrm{kg})$. Hemodynamic and gas exchange indices were measured at baseline, $30 \mathrm{~min}$, and $3 \mathrm{~h}$ of infusion, and $30 \mathrm{~min}$ and $1 \mathrm{~h}$ after L-NAME treatment. L-NAME treatment caused 1) significant increases in mean pulmonary arterial pressure, pulmonary vascular resistance, mean systemic arterial pressure, and systemic vascular resistance for both groups; 2) a similar percentage of increase in pulmonary vascular resistance for the two groups; 3) greater reduction in cardiac output and SV in the GBS compared with the control group; and 4) no significant alterations in arterial partial pressure of oxygen or the difference between alveolar and arterial partial pressure of oxygen for either group. L-Argi-
\end{abstract}

NO is an important modulator of systemic and pulmonary vascular tone $(1-4)$. The synthesis of NO from L-arginine is catalyzed by the enzyme NOS (1). NO stimulates

Received October 25, 1993; accepted July 7, 1994

Correspondence: Ronald L. Gibson, M.D., Ph.D., Department of Pediatrics, RD-20, University of Washington School of Medicine, Seattle, WA 98195.

R.L.G. was supported in part by an American Lung Association Edward Livingston Trudeau Scholar Award. J.I.B. was supported by an American Heart Association of Washington Research Fellowship Award. G.J.R., T.A.S., D.E.M., and W.E.T. were supported in part by NIH Grant HL39157. nine $(1 \mathrm{~g} / \mathrm{kg})$ infusion after $3 \mathrm{~h}$ of GBS infusion $(n=3)$ caused no significant changes in any measured hemodynamic or gas-exchange variable. We conclude that 1 ) endogenous NO synthesis is ongoing during late-phase GBSinduced pulmonary hypertension in neonatal piglets, and 2) NO synthesis is not limited by the substrate L-arginine in this model. NO synthase inhibitors alone appear to be contraindicated in the treatment of neonatal GBS sepsis due to worsening pulmonary hypertension and progressive decline in cardiac output. (Pediatr Res 36: 776-783, 1994)

\section{Abbreviations}

$\mathbf{A}-\mathrm{aDo}_{2}$, difference between alveolar and arterial partial pressure of oxygen

CO, cardiac output

GBS, group B streptococcus

L-NAME, L-N $\omega$-nitro-L-arginine methyl ester

L-NAA, L-N $\omega$-amino-L-arginine

NO, nitric oxide

NOS, nitric oxide synthase

$\mathrm{PaO}_{2}$, arterial partial pressure of oxygen

Pcw, mean pulmonary capillary wedge pressure

Ppa, mean pulmonary arterial pressure

$\Delta \mathbf{P}$, pulmonary vascular driving pressure (Ppa - Pcw)

Psa, mean systemic arterial pressure

PVR, pulmonary vascular resistance

SVR, systemic vascular resistance

TNF- $\alpha$, tumor necrosis factor- $\alpha$

HR, heart rate

SV, stroke volume

$\dot{\mathbf{V}} / \dot{\mathbf{Q}}$, ventilation-perfusion ratio the soluble guanylate cyclase in vascular smooth muscle cells, thereby increasing the intracellular concentrations of cyclic GMP and causing vasodilation (1-4). Endothelial cells contain a constitutive, calcium-dependent form of NOS (1-4). An inducible, calcium-independent isoform of NOS has also been identified in several cell types, including vascular endothelial and smooth muscle cells $(2,5-7)$. Most reports show that the inducible isoform of NOS (2, $5-7$ ) is up-regulated in response to Gram-negative endo- 
toxin and cytokines such as TNF- $\alpha$. Enhanced NO production contributes to endotoxin-mediated systemic hypotension in adult animals $(1,2,5-9)$. There are no published reports on the role of endogenous NO in the control of pulmonary arterial pressure in neonatal animal models of sepsis and pulmonary hypertension.

L-Arginine analogs, such as L-NAME and L-NAA, are competitive antagonists of both isoforms of NOS and inhibit NO synthesis $(4,9)$. These arginine analogs have been used to determine the extent of ongoing NO production during pathologic conditions. In adult dogs administered a single bolus of endotoxin, L-NAA further augmented the endotoxin-induced increase in PVR, suggesting that NO modulates PVR in this model of Gramnegative sepsis (9). There are no reports on the influence of endogenous NO on pulmonary vascular tone during sepsis produced by Gram-positive organisms.

GBS is a Gram-positive pathogen and the most common cause of neonatal sepsis (10-14). GBS sepsis can produce pulmonary hypertension, reduced cardiac output, hypoxemia, and $\dot{\mathrm{V}} / \dot{\mathrm{Q}}$ mismatch in human neonates and neonatal animals (10-12). GBS-induced lung vascular injury also occurs as suggested by GBS invasion of lung capillary walls, intraalveolar hemorrhage and proteinrich pulmonary edema in human infants $(13,14)$, and ultrastructural findings of lung capillary endothelial cell injury in both a piglet and nonhuman primate model of GBS sepsis $(10,15)$. GBS infusion into piglets is delineated into an early $(<1 \mathrm{~h})$ and late phase $(2$ to $6 \mathrm{~h})(11$, $12)$. The late phase is presumably more clinically relevant and is associated with GBS-induced pulmonary hypertension and lung vascular injury, hypoxemia, reduced cardiac output, and increased serum levels of thromboxane $B_{2}$, prostacyclin, and TNF- $\alpha(11,12)$. We reported that exogenous administration of inhaled NO reverses late-phase GBS-induced pulmonary hypertension (16), showing that the pulmonary vascular smooth muscle is not sufficiently injured to impair its response to inhaled NO. However, it is unknown whether sustained GBS infusion injures the pulmonary vasculature sufficiently to reduce endogenous NO production and thereby contribute to GBS-induced pulmonary hypertension. Alternatively, GBS may induce increased NOS activity and endogenous NO production and thereby minimize the degree of pulmonary hypertension.

To determine whether endogenous NO synthesis persists during late-phase GBS sepsis and pulmonary hypertension, we studied the effect of the NOS inhibitor, L-NAME, on hemodynamics and gas exchange in the piglet model. We also studied the effect of $\mathrm{L}$-arginine infusion on late-phase GBS-induced pulmonary hypertenison to determine whether the NOS substrate was a limiting factor.

\section{METHODS}

This study was approved by the University of Washington Animal Care Committee.
Animal preparation. Healthy, mixed-strain piglets (13 \pm $3 \mathrm{~d}, 3.1 \pm 1.0 \mathrm{~kg}$ ) were anesthetized with pentobarbital $(30 \mathrm{mg} / \mathrm{kg})$, paralyzed with pancuronium bromide $(0.3$ $\mathrm{mg} / \mathrm{kg}$ ), heparinized (1000 IU), and mechanically ventilated via a tracheostomy tube with a Harvard ventilator (Harvard Apparatus Co., South Natick, MA). The piglets were ventilated to maintain $\mathrm{PaCO}_{2}$ between 35 and 45 torr. During the 1 -h study period after L-NAME was infused, no ventilator adjustments were made. Catheters were placed in: 1) the aorta, to measure Psa and to sample arterial blood for $\mathrm{pH}$ and blood gas tensions; 2) the left external jugular vein, to infuse GBS; and 3) the pulmonary artery, to measure Ppa, Pcw, and CO (in triplicate by thermodilution using an Edwards 9520A cardiac output computer; Edwards Laboratories, Santa Ana, CA) and to sample mixed venous blood for $\mathrm{pH}$ and blood-gas tensions (5F Swan-Ganz thermodilution catheter). Anesthesia and paralysis were maintained by a continuous infusion of pentobarbital $(3 \mathrm{mg} / \mathrm{kg} / \mathrm{h})$ and hourly doses of pancuronium bromide $(0.3 \mathrm{mg} / \mathrm{kg})$. Vascular and airway pressures were measured using Hewlett-Packard 1280 transducers (Hewlett-Packard, Waltham, MA) referenced to midchest. Vascular pressure measurements were recorded at end-expiration. Piglet body temperatures were maintained at $38.5 \pm 0.5^{\circ} \mathrm{C}$ by a radiant heat source.

GBS preparation. A clinical isolate of type III group B $\beta$-hemolytic streptococci $(\mathrm{COH}-1)$ was prepared as previously described (15). Bacteria were incubated in ToddHewitt broth for $18 \mathrm{~h}$ before each experiment. The broth culture was then centrifuged $(1000 \times \mathrm{g})$ at $4^{\circ} \mathrm{C}$ for $10 \mathrm{~min}$, washed, and resuspended in nonbacteriostatic normal saline. Final concentration of bacteria was determined by OD, using a previously determined plot associating OD with bacteria colony-forming units $/ \mathrm{mL}$.

Experimental protocol. In pilot animals infused with GBS for $3 \mathrm{~h}(n=3)$, we tested a range of L-NAME bolus infusions $(0.3$ to $30 \mathrm{mg} / \mathrm{kg})$. L-NAME caused no significant hemodynamic effects at a dose of $0.3 \mathrm{mg} / \mathrm{kg}$ but caused a sustained increase in PVR and SVR at $3 \mathrm{mg} / \mathrm{kg}$, and doses of 10 or $30 \mathrm{mg} / \mathrm{kg}$ caused a rapid and marked decline in $\mathrm{CO}$ with subsequent death. An L-NAME dose of $3 \mathrm{mg} / \mathrm{kg}$ was selected for the study.

The piglets were randomly assigned to two groups of five each (GBS: $12 \pm 3 \mathrm{~d}$ of age, $3.0 \pm 0.9 \mathrm{~kg}$; control: 13 $\pm 3 \mathrm{~d}$ of age, $3.2 \pm 1.0 \mathrm{~kg}$ ). Measurements taken at each time point included: Psa, Ppa, Pcw, HR, and CO. PVR, $\mathrm{SVR}$, and SV were calculated at each time point (PVR = $\mathrm{Ppa}-\mathrm{Pcw} / \mathrm{CO} ; \mathrm{SVR}=\mathrm{Psa} / \mathrm{CO} ; \mathrm{SV}=\mathrm{CO} / \mathrm{HR})$. Arterial and mixed-venous-blood gases were sampled at each time point. Measurements were taken at baseline, 5, 180, 185,210 , and $240 \mathrm{~min}$ of GBS or normal saline infusion to study the late phase of GBS sepsis; the measurement at 5 min was to establish the acute pulmonary hypertensive response and document the sustained nature of GBSinduced pulmonary hypertension into the late phase. After baseline measurements, the GBS group received a GBS infusion $\left(1.25 \times 10^{9}\right.$ colony-forming units $\left./ \mathrm{kg} / \mathrm{h}\right)$ for 
$240 \mathrm{~min}$. The control group received a 240 -min saline infusion at the same volume as that which the GBS animals had received. A fraction of inspired oxygen of 0.21 was maintained for the $240 \mathrm{~min}$ of GBS or saline infusion. After $180 \mathrm{~min}$ of GBS or saline infusion, a $3-\mathrm{mg} / \mathrm{kg}$ bolus of L-NAME was given. After $240 \mathrm{~min}$ of GBS or saline infusion, the piglets were killed by an overdose of pentobarbital followed by a $\mathrm{KCl}$ infusion.

To test whether L-arginine substrate limitation contributes to GBS-induced pulmonary hypertension, L-arginine $(1 \mathrm{~g} / \mathrm{kg}$ i.v. bolus diluted in $10 \mathrm{~mL}$ normal saline, Sigma Chemical Co., St. Louis, MO) was infused at $3 \mathrm{~h}$ in four additional piglets (GBS: $n=3,2.9 \pm 1.3 \mathrm{~kg}, 9.6 \pm 3.2 \mathrm{~d}$ of age; saline: $n=1,3.2 \mathrm{~kg}, 10 \mathrm{~d}$ of age). The protocol for these animals was otherwise identical.

Statistical analysis. Data are presented as mean $\pm \mathrm{SD}$. To determine the effect of L-NAME, immediate pretreatment (3-h time point), and posttreatment ( $30 \mathrm{~min}$ and $1 \mathrm{~h}$ after L-NAME) values of hemodynamics and gasexchange data were compared by paired $t$ test (SPSS/ PC+ v.4.0, SPSS Inc., Chicago, IL). To determine whether the PVR responses to L-NAME were similar or different in the two experimental manipulations (GBS and saline), the percentages of change in immediate pre- and posttreatment with L-NAME were compared by unpaired $t$ test (SPSS/PC + v.4.0). To determine that baseline hemodynamics and gas exchange values were similar in study and control piglets, intergroup baseline values were compared by unpaired $t$ test (SPSS/PC+ v.4.0). A $p$ value of $<0.05$ was considered significant.

\section{RESULTS}

Effect of $L-N A M E$ on pulmonary hemodynamic indices. Saline infusion (control) caused no significant increases in $\mathrm{Ppa}, \Delta \mathrm{P}$, or PVR above baseline values during the 3 - $\mathrm{h}$ infusion (Fig. 1, Table 1). As expected, GBS infusion caused both acute and sustained increases in $\mathrm{Ppa}, \Delta \mathrm{P}$, and PVR during the $3-\mathrm{h}$ infusion. The increase in PVR for the GBS group was caused by an increase in $\Delta \mathrm{P}$ and a decrease in $\mathrm{CO}$ (Table 1). Compared with values at $3 \mathrm{~h}$ for each group, L-NAME treatment of control and GBS

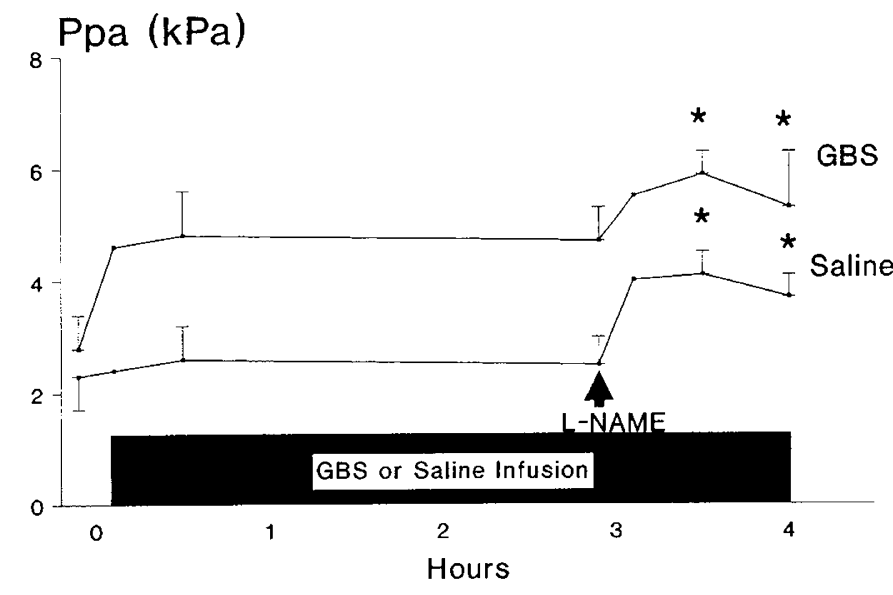

Figure 1. A plot of Ppa before and after L-NAME treatment for both the control and GBS groups. The data are presented as the means \pm SD. The solid black bar represents the 4-h continuous infusion of saline or GBS. The black arrow denotes the the time of the L-NAME infusion. * denotes $p<0.05$ compared with intragroup value after $3 \mathrm{~h}$ of infusion.

piglets caused significant increases in $\mathrm{Ppa}, \Delta \mathrm{P}$, and $\mathrm{PVR}$ at 30 and $60 \mathrm{~min}$ after L-NAME (Fig. 1, Table 1). At 30 min after L-NAME treatment, the control-group Ppa increased by $1.6 \pm 0.4 \mathrm{kPa}, \Delta \mathrm{P}$ increased by $1.5 \pm 0.3 \mathrm{kPa}$, and PVR increased by $3.5 \pm 1.1 \mathrm{kPa} / \mathrm{L} / \mathrm{min}(159 \pm 31 \%)$; for the GBS group, Ppa increased by $1.2 \pm 0.5 \mathrm{kPa}, \Delta \mathrm{P}$ increased by $1.0 \pm 0.4 \mathrm{kPa}$, and PVR at $30 \mathrm{~min}$ after L-NAME increased by $10.6 \pm 3.9 \mathrm{kPa} / \mathrm{L} / \mathrm{min}(171 \pm$ $35 \%$ ). The percentage of increase in PVR caused by L-NAME was not significantly different for the two groups. GBS, but not saline, caused a significant decrease in CO during the 3-h infusion (Table 1). L-NAME treatment of control piglets caused a significant decrease in $\mathrm{CO}$, and L-NAME treatment of GBS piglets caused a further significant decline in CO compared with values at $3 \mathrm{~h}$. Therefore, the increase in PVR after L-NAME treatment in the GBS and control groups was due to both a decrease in $\mathrm{CO}$ and an increase in $\Delta \mathrm{P}$, as evidence for active pulmonary vasoconstriction.

Effect of $L-N A M E$ on systemic hemodynamic indices. Neither saline nor GBS infusions caused significant changes in Psa or SVR above baseline values during the 3-h

Table 1. Pulmonary hemodynamics*

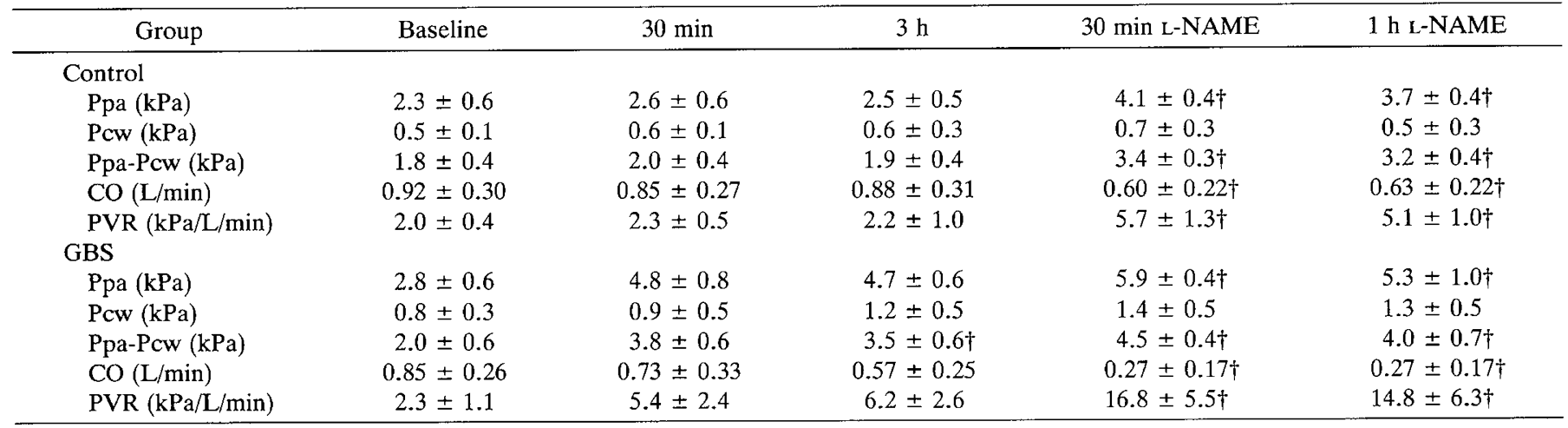

* Values are mean $\pm \mathrm{SD} .30 \mathrm{~min}=30 \mathrm{~min}$ of saline or GBS infusion; $3 \mathrm{~h}=3 \mathrm{~h}$ of saline or GBS infusion; $30 \mathrm{~min} \mathrm{~L}-\mathrm{NAME}=3.5 \mathrm{~h}$ of saline or GBS infusion and $30 \mathrm{~min}$ after L-NAME treatment; $1 \mathrm{~h} \mathrm{L-NAME}=4 \mathrm{~h}$ of saline or GBS infusion and $1 \mathrm{~h}$ after L-NAME treatment.

$\dagger p<0.05$ compared with intragroup value at $3 \mathrm{~h}$ of saline or GBS infusion. 
infusion (Figs. 2 and 3). L-NAME treatment of control and GBS piglets at $3 \mathrm{~h}$ caused significant increases in both Psa and SVR at 30 and $60 \mathrm{~min}$ after L-NAME.

GBS, but not saline, caused a significant increase in HR and a significant decrease in SV during the 3-h infusion (Table 2). L-NAME treatment of control piglets caused a significant decrease in SV with no significant change in HR. L-NAME treatment of GBS piglets caused a further decline in $\mathrm{CO}$ and $\mathrm{SV}$ and a further increase in HR. L-NAME caused a significantly greater reduction in $\mathrm{SV}$ in the GBS compared with control piglets.

Effect of L-NAME on the PVR/SVR ratio. GBS, but not saline, caused a significant increase in the PVR/SVR ratio during the 3 -h infusion (Fig. 4). L-NAME treatment caused a mild but significant increase in the PVR/SVR ratio $30 \mathrm{~min}$ after L-NAME in the control group. L-NAME caused no further increase in the PVR/SVR ratio in the GBS group. This suggests that during late-phase GBS sepsis there are similar levels of NO production from the systemic and pulmonary vascular beds.

Effect of $L-N A M E$ on pulmonary gas exchange. GBS, but not saline, caused a reduction in $\mathrm{pH}, \mathrm{PaO}_{2}$, and $\mathrm{PvO}_{2}$ during the 3-h infusion (Table 3). L-NAME treatment caused no significant changes in arterial or mixedvenous-blood gas tensions in the control group. In the GBS group, L-NAME treatment caused no further decrease in $\mathrm{PaO}_{2}$ but did cause further reductions in mixed venous $\mathrm{Po}_{2}$ and $\mathrm{pH}$. GBS, but not saline, caused a significant increase in $\mathrm{A}-\mathrm{aDo}_{2}$ values during the 3-h infusion (Table 2). L-NAME treatment caused no significant changes in $\mathrm{A}-\mathrm{aDo}_{2}$ values for either group compared with 3 -h pretreatment values, suggesting that L-NAME caused no significant alterations in ventilation-perfusion matching in control or GBS piglets.

Effect of L-arginine on hemodynamics and gas exchange. Three neonatal piglets were infused with GBS for $3 \mathrm{~h}$ as above and then administered $1 \mathrm{~g} / \mathrm{kg}$ L-arginine by i.v. infusion. L-Arginine caused no significant changes in any

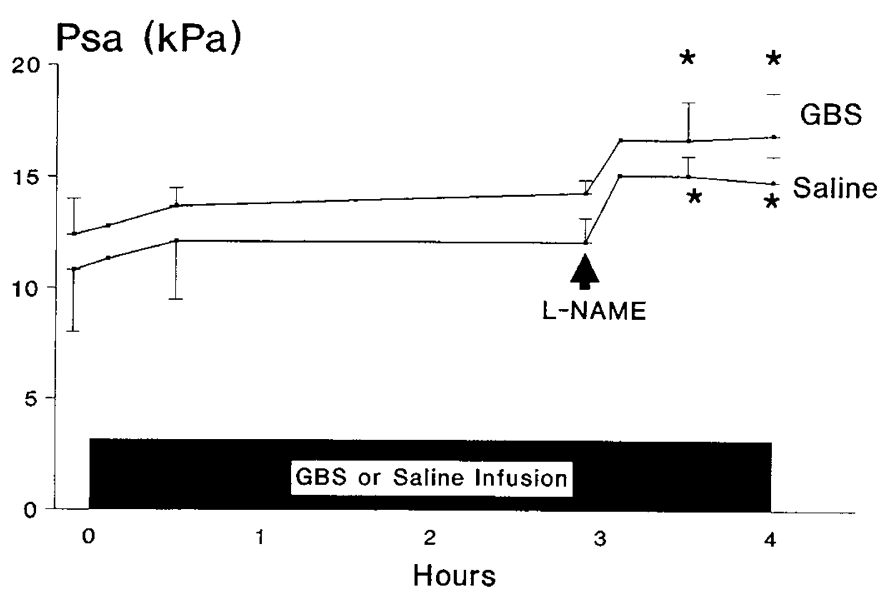

Figure 2. A plot of Psa before and after L-NAME treatment for both the control and GBS groups. The data are presented as the means \pm SD. The solid black bar represents the 4-h continuous infusion of saline or GBS. The black arrow denotes the time of the L-NAME infusion. * denotes $p<0.05$ compared with intragroup value after 3 h of infusion.
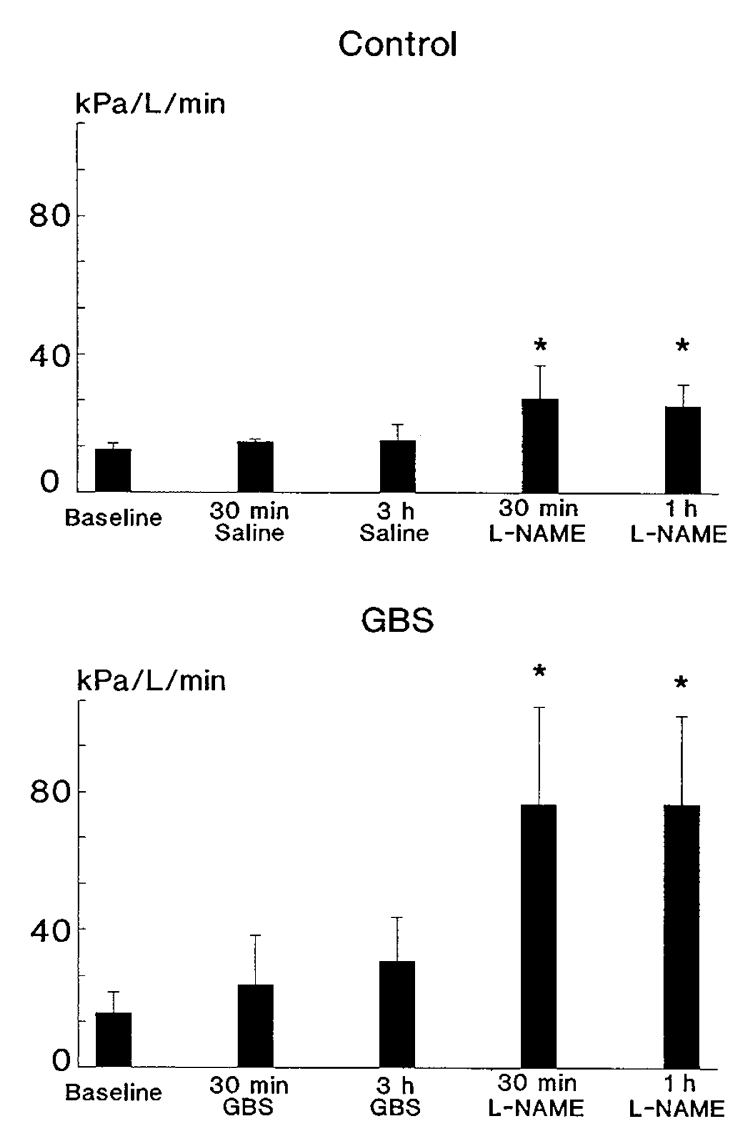

Figure 3. Histogram plots of SVR before and after L-NAME treatment for both the control and GBS groups. The data are expressed as the means $\pm \mathrm{SD} .30 \mathrm{~min}, 30 \mathrm{~min}$ of saline or GBS infusion; $3 \mathrm{~h}, 3 \mathrm{~h}$ of saline or GBS infusion; 30 min $L-N A M E, 3.5 \mathrm{~h}$ of saline or GBS infusion and 30 min after L-NAME treatment; $1-h L-N A M E, 4 \mathrm{~h}$ of saline or GBS infusion and $1 \mathrm{~h}$ after L-NAME treatment. * denotes $p<0.05$ compared with intragroup values at $3 \mathrm{~h}$.

measured hemodynamic or gas-exchange variable (Table 4). In a single control, saline-infused piglet, $1 \mathrm{~g} / \mathrm{kg} \mathrm{L-ar-}$ ginine, caused no significant changes in any measured variable. We conclude that endogenous NO production is not limited by L-arginine concentrations during late-phase GBS-induced pulmonary hypertension.

\section{DISCUSSION}

In a neonatal piglet model of sustained GBS sepsis, inhibition of NOS by L-NAME caused 1) further increases in Ppa, $\triangle \mathrm{P}, \mathrm{PVR}$, and SVR, with no change in the $\mathrm{PVR} / \mathrm{SVR}$ ratio; 2) further reductions in $\mathrm{CO}$ and $\mathrm{SV}$; and $3)$ a reduction in mixed-venous-oxygen tension without a change in ventilation-perfusion matching. L-NAME treatment caused similar increases in $\triangle \mathrm{P}$ and PVR in GBS and control piglets. These data provide indirect evidence that endogenous NO production persists during sustained GBS infusion in piglets and that endogenous NO reduces pulmonary vascular hypertension in this model of latephase GBS sepsis. However, we cannot make conclusions about the degree of endogenous NO synthesis during sustained GBS infusion, i.e. increased, decreased, or unchanged. We did not include an additional control group of sustained GBS infusion for $4 \mathrm{~h}$ without $\mathrm{L}-\mathrm{NAME}$ 
Table 2. Effect of $L-N A M E$ on cardiac function*

\begin{tabular}{|c|c|c|c|c|c|}
\hline Group & Baseline & $30 \mathrm{~min}$ & $3 \mathrm{~h}$ & $30 \mathrm{~min}$ L-NAME & $1 \mathrm{~h} \mathrm{~L}$-NAME \\
\hline \multicolumn{6}{|l|}{ Control } \\
\hline $\mathrm{CO}(\mathrm{L} / \mathrm{min})$ & $0.92 \pm 0.35$ & $0.85 \pm 0.27$ & $0.88 \pm 0.37$ & $0.60 \pm 0.22 \dagger$ & $0.63 \pm 0.22 \dagger$ \\
\hline HR (beats/min) & $225 \pm 44$ & $226 \pm 43$ & $212 \pm 35$ & $219 \pm 32$ & $220 \pm 30$ \\
\hline Stroke vol (mL) & $4.3 \pm 2.0$ & $4.0 \pm 1.7$ & $4.4 \pm 2.8$ & $2.9 \pm 1.4 \dagger$ & $3.0 \pm 1.3 \dagger$ \\
\hline \multicolumn{6}{|l|}{ GBS } \\
\hline $\mathrm{CO}(\mathrm{L} / \mathrm{min})$ & $0.85 \pm 0.26$ & $0.73 \pm 0.38 \ddagger$ & $0.57 \pm 0.35 \S$ & $0.27 \pm 0.17 \dagger$ & $0.27 \pm 0.17 \dagger$ \\
\hline HR (beats/min) & $201 \pm 32$ & $215 \pm 34$ & $228 \pm 24 \ddagger$ & $241 \pm 21 \dagger$ & $271 \pm 38 \|$ \\
\hline Stroke vol (mL) & $4.3 \pm 1.2$ & $3.5 \pm 1.8 \ddagger$ & $2.5 \pm 1.5 \S$ & $1.1 \pm 0.8 \|$ & $1.1 \pm 0.9 \|$ \\
\hline
\end{tabular}

$*$ Values are as mean \pm SD. Abbreviations same as for Table 1 .

$\dagger p<0.05$ compared with intragroup 3-h data.

$\ddagger p<0.05$ compared with intragroup baseline value.

$\S p<0.05$ compared with intragroup baseline value and comparable intergroup value.

$\| p<0.05$ compared with intragroup 3-h data and intergroup value.

treatment at $3 \mathrm{~h}$, because, in using the same model, we previously reported no significant changes in pulmonary hemodynamics between 3 and $4 \mathrm{~h}$ of sustained GBS infusion (16). In addition, the rapid hemodynamic responses to L-NAME in both the control and GBS groups ( $<5 \mathrm{~min})$ suggests that the alterations in pulmonary hemodynamics are due to the L-NAME bolus and not the continuation of GBS infusion. Rudinsky et al. (17) have published a preliminary report on the effect of $\mathrm{L}-\mathrm{N}^{\mathrm{G}}$-nitro-

\section{Control}

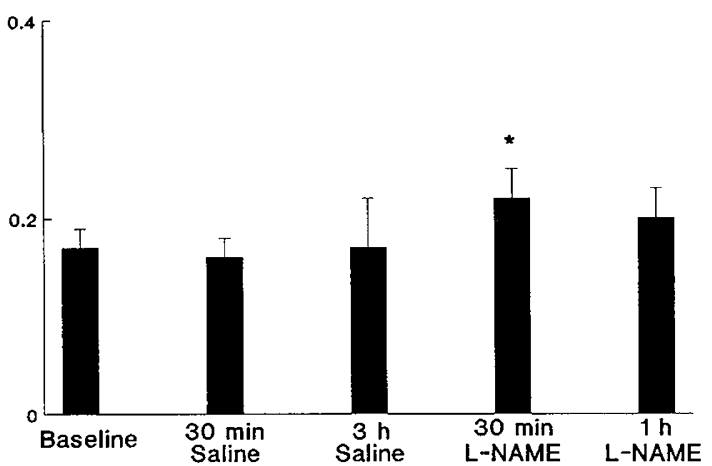

GBS

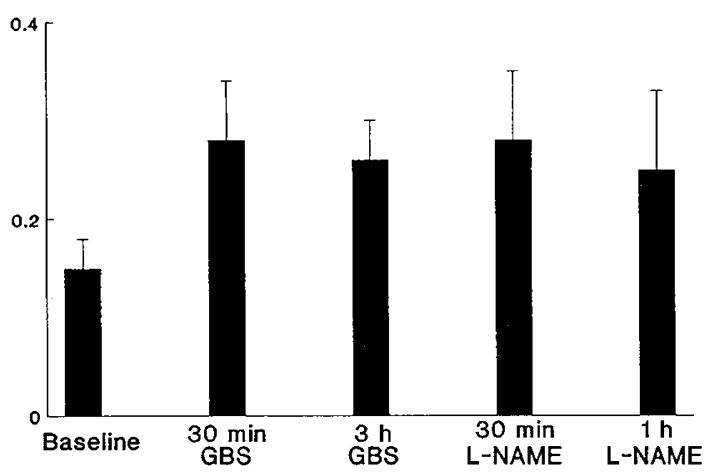

Figure 4. Histogram plots of the PVR/SVR ratio before and after L-NAME treatment for both the control and GBS groups. The data are expressed as the means $\pm \mathrm{SD}$. $30 \mathrm{~min}, 30 \mathrm{~min}$ of saline or GBS infusion; $3 h, 3 \mathrm{~h}$ of saline or GBS infusion; $30 \mathrm{~min} L$-NAME, $3.5 \mathrm{~h}$ of saline or GBS infusion and $30 \mathrm{~min}$ after L-NAME treatment; $1 \mathrm{~h} \mathrm{~L}-N A M E, 4 \mathrm{~h}$ of saline or GBS infusion and $1 \mathrm{~h}$ after L-NAME treatment. ${ }^{*}$ denotes $p<$ 0.05 compared with intragroup values at $3 \mathrm{~h}$.
L-arginine in a piglet model of acute GBS sepsis. The hemodynamic effects were similar to our study, inasmuch as GBS + $\mathrm{L}-\mathrm{N}^{\mathrm{G}}$-nitro-L-arginine caused a marked increase in Ppa and a marked decrease in CO compared with GBS alone. In our study, L-arginine infusion after 3 $\mathrm{h}$ of sustained GBS infusion did not cause any significant changes in hemodynamic or gas-exchange variables. $\mathrm{Ru}-$ dinsky et al. (18) have also published preliminary data that $\mathrm{L}$-arginine treatment $(300 \mathrm{mg} / \mathrm{kg})$ of acute GBS sepsis in piglets causes partial attenuation of GBS-induced pulmonary hypertension and mild reduction of the PVR/ SVR ratio with no effect on CO or Psa. These findings differ from our observation of $\mathrm{x}$-arginine treatment in a model of late-phase, sustained GBS pulmonary hypertension. The reason for the discrepancy is uncertain, with possibilities including 1) increased duration of GBS infusion and increased number of vasoconstrictive mediators in the late-phase model $(11,12,16)$ and 2) differing GBS doses. We conclude that 1 ) endogenous NO synthesis persists during late-phase GBS-induced pulmonary hypertension in neonatal piglets, and 2) NO production is not limited by L-arginine concentrations during late-phase GBS-induced pulmonary hypertension.

The lack of direct measurement of NO-related parameters, such as plasma nitrates, is a limitation of our study. In the absence of these measures, we cannot be certain that the dose of L-NAME used in our study $(3 \mathrm{mg} / \mathrm{kg})$ caused complete inhibition of NOS activity in this piglet model of GBS-induced pulmonary hypertension. L-NAME doses of 1 to $3 \mathrm{mg} / \mathrm{kg}$ have previously been reported to markedly inhibit NO production in rats and cats in vivo, with doses of 10 to $30 \mathrm{mg} / \mathrm{kg}$ causing little additional hemodynamic alterations $(4,5,19)$. We selected an L-NAME dose of $3 \mathrm{mg} / \mathrm{kg}$ based on the literature and our pilot studies in piglets in which doses $>3$ $\mathrm{mg} / \mathrm{kg}$ caused hemodynamic instability and death before completing the 4-h protocol. If the dose of L-NAME used in our study caused submaximal inhibition of NOS activity, this would only underestimate the contribution of endogenous NO to late-phase GBS-induced pulmonary hypertension. This hypothetical scenario would not alter our conclusion that endogenous NO synthesis persists during late-phase GBS-induced pulmonary hypertension. 
Table 3. Effect of $L-N A M E$ on gas exchange*

\begin{tabular}{|c|c|c|c|c|c|}
\hline Group & Baseline & $30 \mathrm{~min}$ & $3 \mathrm{~h}$ & 30 min L-NAME & $1 \mathrm{~h} \mathrm{~L}$-NAME \\
\hline \multicolumn{6}{|l|}{ Control } \\
\hline $\mathrm{pH}$ & $7.46 \pm 0.02$ & $7.45 \pm 0.03$ & $7.44 \pm 0.06$ & $7.44 \pm 0.04$ & $7.45 \pm 0.03$ \\
\hline $\mathrm{PaCO}_{2}(\mathrm{kPa})$ & $4.5 \pm 0.3$ & $4.9 \pm 0.3$ & $5.1 \pm 0.5$ & $4.9 \pm 0.5$ & $4.9 \pm 0.4$ \\
\hline $\mathrm{PaO}_{2}(\mathrm{kPa})$ & $10.4 \pm 1.2$ & $10.3 \pm 1.1$ & $10.5 \pm 1.5$ & $10.0 \pm 1.1$ & $10.1 \pm 1.2$ \\
\hline $\mathrm{PvO}_{2}(\mathrm{kPa})$ & $5.1 \pm 1.3$ & $5.1 \pm 1.0$ & $5.1 \pm 1.0$ & $4.5 \pm 0.8$ & $4.7 \pm 0.6$ \\
\hline $\mathrm{A}-\mathrm{aDO}_{2}(\mathrm{kPa})$ & $4.0 \pm 0.6$ & $3.7 \pm 0.4$ & $3.6 \pm 0.5$ & $4.0 \pm 0.7$ & $3.9 \pm 0.5$ \\
\hline \multicolumn{6}{|l|}{ GBS } \\
\hline $\mathrm{pH}$ & $7.44 \pm 0.02$ & $7.45 \pm 0.04$ & $7.44 \pm 0.04$ & $7.41 \pm 0.07 \dagger$ & $7.34 \pm 0.06 \ddagger$ \\
\hline $\mathrm{PaCO}_{2}(\mathrm{kPa})$ & $4.8 \pm 0.6$ & $5.2 \pm 1.3$ & $4.8 \pm 0.6$ & $4.8 \pm 0.5$ & $5.3 \pm 0.9 \ddagger$ \\
\hline $\mathrm{PaO}_{2}(\mathrm{kPa})$ & $10.0 \pm 1.0$ & $9.1 \pm 2.0 \S$ & $8.7 \pm 1.9 \S$ & $8.5 \pm 1.7 \S$ & $8.3 \pm 1.6 \S$ \\
\hline $\mathrm{PvO}_{2}(\mathrm{kPa})$ & $5.3 \pm 0.8$ & $4.7 \pm 0.7 \dagger$ & $4.4 \pm 0.8 \S$ & $3.1 \pm 0.3 \|$ & $3.3 \pm 0.5 \|$ \\
\hline $\mathrm{A}-\mathrm{aDo} \mathrm{O}_{2}(\mathrm{kPa})$ & $4.1 \pm 0.7$ & $4.5 \pm 0.9$ & $5.6 \pm 0.8 \dagger$ & $5.6 \pm 0.6 \S$ & $5.3 \pm 0.7 \S$ \\
\hline
\end{tabular}

* Values are mean \pm SD. Abbreviations same as for Table 1 .

$\dagger p<0.05$ compared with intragroup baseline value.

$\ddagger p<0.05$ compared with intragroup 3-h data.

$\S p<0.05$ compared with intragroup baseline value and comparable intergroup value.

$\| p<0.05$ compared with intragroup 3-h data and intergroup value.

Analogs of L-arginine have been used to treat endotoxin-mediated shock in animal models and humans $(2,5-8$, $20,21)$. The reports are conflicting as to their benefit, with some discrepancies possibly due to the degree of NOS inhibition and animal model used. Some studies report lethal complications with marked decline in $\mathrm{CO}$ and SV (9), whereas others report reversal of shock (8) or increased survival in a murine model of Escherichia coli sepsis (22). L-NAA treatment of adult control dogs resulted in similar findings to L-NAME treatment of our control piglets. These effects include depressed $\mathrm{CO}$ and reduced SV with no change in HR (9). The effect of L-NAME on cardiac function was more deleterious during late-phase GBS, with greater reduction in CO and SV and an increase in HR. The cause of the progressive cardiac dysfunction produced by NOS inhibition may be multifactorial, including 1 ) coronary artery vasoconstriction with myocardial ischemia and reduced contractility $(23-26), 2)$ reduced endocardial cell production of NO with potential decreased myocardial performance (27), and 3 ) increased cardiac afterload with the acute increase in PVR and SVR $(28,29)$. The neonate seems particularly susceptible to acute cardiac afterload stress $(28,29)$, and the combination of GBS sepsis with limited cardiac reserve and an acute afterload stress may have precipitated the marked decline in $\mathrm{CO}$.

There are limited studies on the effect of NOS inhibitors on pulmonary gas exchange $(9,30,31)$. In adult dogs,
L-NAA treatment caused a reduction in $\mathrm{PvO}_{2}$ with no other significant changes in gas exchange (9). In an adult animal model of oleic acid lung injury with marked intrapulmonary shunt and ventilation-perfusion mismatch, $N^{G}$-nitro-L-arginine treatment caused no changes in $\mathrm{PaO}_{2}$, venous $\mathrm{PO}_{2}$, or intrapulmonary shunt (30). L-NAME caused no significant alterations in $\mathrm{A}-\mathrm{aDO}_{2}$ in control or GBS piglets but did reduce venous $\mathrm{Po}_{2}$ in the GBS piglets, presumably secondary to progressive decrease in systemic $\mathrm{O}_{2}$ delivery due to decreased CO. These prior studies and our data suggest that inhibition of NOS causes no significant changes in ventilation-perfusion matching in animal models of sepsis with pulmonary hypertension. However, in an adult sheep model of endotoxic shock with mild hypoxemia and increased intrapulmonary shunt, L-NAME caused return to baseline values for $\mathrm{PaO}_{2}$ and intrapulmonary shunt fraction (31). The reason for this discrepancy is uncertain, but factors may include: 1) age of animals $(32,33)$; 2) species (6); 3) L-NAME dose; and, perhaps most importantly, 4) the minimal intrapulmonary shunt (1 to $3 \%$ ) in our neonatal piglet model at baseline or during GBS infusion (16). Inhibition of NO production by L-NAME may result in redistribution of pulmonary blood flow away from shunt and low $\dot{\mathrm{V}} / \dot{\mathrm{Q}}$ regions. We speculate that the minimal intrapulmonary shunt and hypoxemia observed in our piglet model of GBSinduced pulmonary hypertension did not provide

Table 4. Effect of L-arginine infusion during GBS infusion*

\begin{tabular}{lccccccccc}
\hline pH & $\begin{array}{c}\mathrm{PaCO}_{2} \\
(\mathrm{kPa})\end{array}$ & $\begin{array}{c}\mathrm{PaO}_{2} \\
(\mathrm{kPa})\end{array}$ & $\begin{array}{c}\mathrm{Pvo}_{2} \\
(\mathrm{kPa})\end{array}$ & $\begin{array}{c}\text { Psa } \\
(\mathrm{kPa})\end{array}$ & $\begin{array}{c}\mathrm{HR} \\
(\text { beats/min })\end{array}$ & $\begin{array}{c}\mathrm{Ppa} \\
(\mathrm{kPa})\end{array}$ & $\begin{array}{c}\mathrm{CO} \\
(\mathrm{L} / \mathrm{min})\end{array}$ & $\begin{array}{c}\mathrm{PVR} \\
(\mathrm{kPa} / \mathrm{L} / \mathrm{min})\end{array}$ \\
\hline Baseline & $7.42 \pm 0.03$ & $4.7 \pm 0.3$ & $11.0 \pm 1.2$ & $5.5 \pm 0.8$ & $11.5 \pm 2.4$ & $207 \pm 25$ & $2.4 \pm 0.5$ & $0.87 \pm 0.31$ & $2.0 \pm 0.4$ \\
30' GBS & $7.43 \pm 0.06$ & $4.8 \pm 0.4$ & $9.5 \pm 1.4$ & $4.8 \pm 0.8$ & $11.2 \pm 2.7$ & $220 \pm 35$ & $4.4 \pm 1.1$ & $0.75 \pm 0.40$ & $4.5 \pm 0.6$ \\
3 h GBS & $7.40 \pm 0.05$ & $5.1 \pm 0.3$ & $8.9 \pm 0.9$ & $4.5 \pm 1.0$ & $10.4 \pm 3.1$ & $216 \pm 28$ & $4.3 \pm 0.9$ & $0.60 \pm 0.27$ & $5.4 \pm 0.8$ \\
30' ARG & $7.42 \pm 0.04$ & $5.1 \pm 0.3$ & $8.8 \pm 1.1$ & $4.4 \pm 1.1$ & $10.5 \pm 2.5$ & $224 \pm 32$ & $4.5 \pm 0.9$ & $0.58 \pm 0.19$ & $5.7 \pm 0.9$ \\
1 h ARG & $7.39 \pm 0.06$ & $5.2 \pm 0.4$ & $8.3 \pm 1.2$ & $4.4 \pm 0.9$ & $10.3 \pm 2.9$ & $218 \pm 36$ & $4.1 \pm 1.2$ & $0.61 \pm 0.23$ & $4.9 \pm 1.0$ \\
\hline
\end{tabular}

* Values are mean $\pm \mathrm{SD}$. There were no significant changes in any parameter after L-arginine infusion. $30^{\prime}$ GBS $=30 \mathrm{~min}$ GBS infusion; $3 \mathrm{~h}$ GBS $=3 \mathrm{~h}$ GBS infusion; $30^{\prime} \mathrm{ARG}=3.5 \mathrm{~h}$ GBS infusion and $30 \mathrm{~min}$ after $1 \mathrm{~g} / \mathrm{kg} \mathrm{L}$-arginine i.v. bolus; $1 \mathrm{~h} \mathrm{ARG}=4 \mathrm{~h} \mathrm{GBS}$ infusion and $1 \mathrm{~h}$ after $\mathrm{L}$-arginine infusion. 
enough low $\dot{\mathrm{V}} / \dot{\mathrm{Q}}$ regions for $\mathrm{L}-\mathrm{NAME}$ to modulate regional pulmonary blood flow.

Endotoxin treatment both in vitro and in vivo causes increased NOS activity and enhanced NO production, according to most reports $(2,5-9)$. However, others have observed endotoxin treatment in vivo caused decreased endothelial-dependent relaxation of adult canine or guinea pig systemic arterial rings $(34,35)$. The reports that endotoxin reduces NO production may be due to the down-regulation of the constitutive isoform of NOS acutely, and the reports showing that endotoxin increases NO production may be due to up-regulation of the inducible isoform of NOS after more prolonged endotoxin exposure. In addition to the dose and duration of endotoxin treatment, other factors that may alter NO production include vascular endothelial or smooth muscle injury, species, and the assays used to measure endothelialderived relaxation factor activity. Some reports have shown organ-specific patterns of NOS induction by endotoxin, with the lung being a major source of inducible NOS $(5,6)$. Endotoxin treatment in vivo can increase the inducible isoform of NOS by $3 \mathrm{~h}(5,6)$. Most studies of NOS inhibitors in models of sepsis have focused on systemic hemodynamics and did not report changes in pulmonary hemodynamics caused by NOS inhibition (2, $5,8)$. However, after endotoxin treatment of adult dogs, a continuous infusion of LNAA caused a sustained and progressive increase in PVR and SVR and further reductions in CO, HR, and SV (9). In this same study, there were no pulmonary hemodynamic data presented for a group of saline-infused control dogs treated with L-NAA, and no direct statistical comparisons were made between the saline- and endotoxin-treated groups. In our study using GBS, a Gram-positive pathogen, NOS inhibition caused no change in the PVR/SVR ratio, suggesting a similar effect on the pulmonary and systemic vascular beds. We did not directly measure NOS activity or NO metabolites and can only conclude that NO contributes to both pulmonary and systemic vascular tone during GBS sepsis. Possible explanations for the different response to NOS inhibition include 1) age of animals $(32,33), 2)$ species-specific responses to NOS inhibition (36), and 3) Gram-positive pathogen compared with Gram-negative endotoxin.

A recent study detected increased circulating NO metabolites in neonates with both Gram-positive and Gramnegative sepsis, and the plasma nitrate levels were highest in those patients with shock (37). Continuous NO synthesis by vascular endothelial or smooth muscle cells appears to modulate pulmonary and systemic vascular tone in this piglet model of neonatal sepsis and pulmonary hypertension. Late-phase GBS sepsis in neonatal piglets is also associated with increased serum levels of the potent vasodilator, prostacyclin, a potent vasoconstrictor, thromboxane $\mathrm{A}_{2}$, and a proinflammatory and vasoactive cytokine, TNF- $\alpha(11,12)$. The degree of latephase GBS-induced pulmonary hypertension is presumably an integrated function of these multiple vasoactive stimuli, regional alveolar hypoxia, and pulmonary blood flow. The multiple circulating vasoconstrictive stimuli in this model of GBS sepsis may in part explain the higher pre- and post-L-NAME values for PVR and SVR in the GBS group compared with the control group. Endogenous NO production has been measured to be 8 to 15 parts per billion of exhaled gas in humans and animals (38). These endogenous concentrations are not sufficient to override multiple vasoconstrictive stimuli and normalize pulmonary artery pressure during late-phase GBS sepsis.

Previous studies have suggested that the NOS substrate, L-arginine, is not a limiting factor for NOSinduced vasodilation under basal conditions $(39,40)$. However, there are limited studies on the use of L-arginine infusions in in vivo models of neonatal sepsis and pulmonary hypertension (18). In our study, L-arginine infusion at $1 \mathrm{~g} / \mathrm{kg}$ had no affect on late-phase GBSinduced pulmonary hypertension. These data suggest that L-arginine is not a limiting factor for NOS-induced vasodilation in this model of neonatal sepsis and pulmonary hypertension. One potential explanation is that there are adequate levels of $\mathrm{L}$-arginine in plasma to saturate the NOS of both endothelial and vascular smooth muscle cells (41). Further study of the signals for NO synthesis may lead to more potent stimulators of endogenous NO for the treatment of pulmonary hypertension. Despite the reports of increased NO production in neonatal sepsis with shock (37), NOS inhibitors were deleterious in this model of neonatal sepsis due to progressive decline in cardiac output and worsening pulmonary hypertension. Combining inhaled NO with systemic NOS inhibitors may reduce the untoward effect of worsening pulmonary hypertension. However, the use of NOS inhibitors alone appears to be contraindicated in the treatment of human newborns with GBS sepsis.

\section{REFERENCES}

1. Moncada S, Palmer RMJ, Higgs EA 1991 Nitric oxide: physiology, pathophysiology, and pharmacology. Pharmacol Rev 43:109-142

2. Palmer RMJ 1993 The discovery of nitric oxide in the vessel wall: a unifying concept in the pathogenesis of sepsis. Arch Surg 128:396-401

3. Ignarro LJ 1990 Biosynthesis and metabolism of endothelium-derived nitric oxide. Annu Rev Pharmacol Toxicol 30:535-560

4. Rees DD, Palmer RMJ, Schultz R, Hodson HF, Moncada S 1990 Characterization of three inhibitors of endothelial nitric oxide synthase in vitro and in vivo. Br J Pharmacol 101:746-752

5. Szabo C, Mitchell JA, Thiemermann C, Vane JR 1993 Nitric oxide-mediated hyporeactivity to noradrenaline precedes the induction of nitric oxide synhyporeactivity to noradrenaline precedes the induction

6. Salter M, Knowles RG, Moncada S 1991 Widespread tissue distribution, species distribution and changes in activity of calcium-dependent and calcium-independent nitric oxide synthases. FEBS Lett 291:145-149

7. Gross SS, Jaffe EA, Levi R, Kilbourn RG 1991 Cytokine-activated endothelial cells express an isotype of nitric oxide synthase which is tetrahydrobiopterin-dependent, calmodulin-independent and inhibited by arginine analogs with a rank order potency characteristic of activated macrophages. Biochem Biophys Res Commun 178:823-829

8. Kilbourn RG, Jubran A, Gross SS, Griffith OW, Levi R, Adams J, Lodato RF 1990 Reversal of endotoxin-mediated shock by $\mathrm{N}^{\mathrm{G}}$-methyl-L-arginine, an inhibitor of nitric oxide synthesis. Biochem Biophys Res Commun 172:11321138

9. Cobb JP, Natanson C, Hoffman WD, Lodato RF, Banks S, Koev CA, Solomon MA, Elin RJ, Hosseini JM, Danner RL $1992 \mathrm{~N}$-amino-L-arginine, an inhibitor of nitric oxide synthase, raises vascular resistance but increases mortality rates in awake canines challenged with endotoxin. J Exp Med 176:1175-1182 
10. Rojas J, Larrson LE, Hellerqvist CG, Brigham KL, Gray ME, Stahlman MT 1983 Pulmonary hemodynamic and ultrastructural changes associated with group B streptococcal sepsis in adult sheep and newborn lambs. Pediatr Res 17:1002-1008

11. Runkle B, Goldberg RN, Streitfeld MM, Clark MR, Buron E, Stetzer ES, Bancalari E 1984 Cardiovascular changes in group B streptococcal sepsis in the piglet: response to indomethacin and the relationship to prostacyclin and thromboxane $\mathrm{A}_{2}$. Pediatr Res 18:874-978

12. Gibson RL, Henderson Jr WR, Truog WE, Redding GJ 1992 Group B streptococcal sepsis in piglets: effect of combined pentoxifylline and indomethacin pretreatment. Pediatr Res 31:222-227

13. Katzenstein A, Davis C, Braude A 1976 Pulmonary changes in neonatal sepsis due to group B beta-hemolytic streptococcus: relation to hyaline membrane disease. J Infect Dis 133:430-435

14. Becroft DMO, Farmer K, Mason GH, Stewart JH 1976 Perinatal infections by group B beta-hemolytic streptococci. Br J Obstet Gynaecol 83:960-965

15. Gibson RL, Lee MK, Soderland C, Chi EY, Rubens CE 1993 Group B streptococci invade endothelial cells: type III capsular polysaccharide attenuates invasion. Infect Immun 61:478-485

16. Berger JI, Gibson RL, Redding GJ, Standaert TA, Clarke WR, Truog WE 1993 Effect of inhaled nitric oxide during group B streptococcal sepsis in piglets. Am Rev Respir Dis 147:1080-1086

17. Rudinsky B, Bell A, Randle C, Lozon M, Hipps B, Meadow W 1993 Inhibition of endothelium-derived relaxation factor (EDRF) during group B streptococcal sepsis is very bad for piglets. Pediatr Res 33:40A(abstr)

18. Rudinsky B, Bell A, Randle C, Lozon M, Hipps B, Meadow W 1993 L-Arginine ameliorates pulmonary and systemic hemodynamic deterioration during group B streptococcal sepsis in piglets. Pediatr Res 33:40A(abstr)

19. Persson MG, Gustafsson LE, Wiklund NP, Moncada S, Hedqvist P 1990 Endogenous nitric oxide as a probable modulator of pulmonary circulation and hypoxic pressor response in vivo. Acta Physiol Scand 140:449-457

20. Thiemermann C, Vane J 1990 Inhibition of nitric oxide synthesis reduces the hypotension induced by bacterial lipopolysaccharide in the rat in vivo. Eur $\mathrm{J}$ Pharmacol 182:591-595

21. Wright CE, Rees DD, Moncada S 1992 Protective and pathological roles of nitric oxide in endotoxin shock. Cardiovasc Res 26:48-57

22. Teale DM, Atkinson AM 1992 Inhibition of nitric oxide synthesis improves survival in a murine peritonitis model of sepsis that is not cured by antibiotics alone. J Antimicrob Chemother 30:839-842

23. Hodgson JM, Marshall JJ 1989 Direct vasoconstriction and endotheliumdependent vasodilation: mechanisms of acetylcholine effects on coronary flow and arterial diameter in patients with nonstenotic coronary arteries. Circulation 79:1043-1051

24. Chester AH, O’Neil GS, Moncada S, Tadjkarimi S, Yocoub MH 1990 Low basal and stimulated release of nitric oxide in atherosclerotic epicardial coronary arteries. Lancet 336:897-900
25. Amezcua JL, Palmer RMJ, de Souza BM, Moncada S 1989 Nitric oxide synthesized from $\mathrm{L}$-arginine regulates vascular tone in the coronary circulation of the rabbit. Br J Pharmacol 97:1119-1124

26. Benyo Z, Kiss G, Szabo C, Csaki C, Kovach AGB 1991 Importance of basal nitric oxide synthesis in regulation of myocardial blood flow. Cardiovasc Res 25:700-703

27. Smith JA, Radomski MW, Schulz R, Moncada S, Lewis MJ 1993 Porcine ventricular endocardial cells in culture express the inducible form of nitric oxide synthase. Br J Pharmacol 108:1107-1110

28. van Hare GF, Hawkins JA, Schmidt KG, Rudolph AM 1990 The effects of increasing mean arterial pressure on left ventricular output in newborn lambs. Circ Res 67:78-83

29. Berman W, Christensen D 1983 Effects of acute preload and afterload stress on myocardial function in newborn and adult sheep. Biol Neonate 43:61-66

30. Leeman M, Zegers de Beyl V, Gilbert E, Melot C, Naeije R 1993 Is nitric oxide released in oleic acid lung injury? J Appl Physiol 74:650-654

31. Meyer J, Traber LD, Nelson S, Lentz CW, Nakazawa H, Herndon DN, Noda H, Traber DL 1992 Reversal of hyperdynamic response to continuous endotoxin administration by inhibition of NO synthesis. J Appl Physiol 73:324-328

32. Zellers TM, Vanhoutte PM 1991 Endothelial-dependent relaxations of piglet pulmonary arteries augment with maturation. Pediatr Res 30:176-180

33. Perrault T, DeMarte J 1993 Maturational changes in endothelial-dependent relaxations in newborn piglet pulmonary circulation. Am J Physiol 264:H302_ $\mathrm{H} 309$

34. Wylam ME, Samsel RW, Umans JG, Mitchell RW, Leff AR, Schumasker PT 1990 Endotoxin in vivo impairs endothelium-dependent relaxation of canine arteries in vitro. Am Rev Respir Dis 142:1263-1267

35. Parker JL, Adams HR 1993 Selective inhibition of endothelium-dependent vasodilator capacity by Escherichia coli endotoxemia. Circ Res 72:539-551

36. van Gelderen EM, Heiligers JPC, Saxena PR 1991 Haemodynamic changes and acetylcholine-induced hypotensive responses after $\mathrm{N}^{\mathrm{G}}$-nitro-L-arginine methyl ester in rats and cats. Br J Pharmacol 103:1899-1904

37. Shi Y, Li H-Q, Shen C-K, Wang J-H, Qin S-W, Liu R, Pan J 1993 Plasma nitric oxide levels in newborn infants with sepsis. J Pediatr 123:435-438

38. Gustafsson LE, Leone AM, Persson MG, Wiklund NP, Moncada S 1991 Endogenous nitric oxide is present in the exhaled air of rabbits, guinea pigs, and humans. Biochem Biophys Res Commun 181:852-857

39. Amezcua JL, Palmer RMJ, DeSouza BM, Moncada S 1989 Nitric-oxide synthesized from L-arginine regulates vascular tone in the coronary circulation of the rabbit. Br J Pharmacol 97:1119-1124

40. Rees DD, Palmer RMJ, Moncada S 1989 Role of endothelium derived nitric oxide in the regulation of blood pressure. Proc Natl Acad Sci USA 86:33753378

41. Pasini FL, Frigerio C, De Giorgi L, Blardi P, Di Perri T $1992_{\text {L-Arginine }}$ plasma concentrations in hypercholesterolaemia. [letter] Lancet 340:549 